\section{Psicologia Escolar \\ e Educacional}

ARTIGO

DOI: http://dx.doi.org/10.1590/2175-35392021222921

Localizador - e222921

\title{
DEBATENDO SOBRE MEDICALIZAÇÃO COM DOCENTES EM ESCOLAS PÚBLICAS E PRIVADAS
}

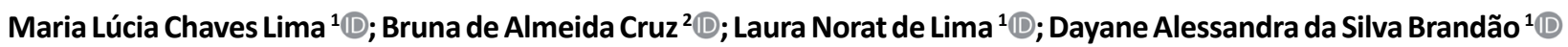

\section{RESUMO}

Este estudo teve o intuito de conhecer de que forma o tema da medicalização da educação tem sido abordado e debatido entre profissionais da educação, mais especificamente as/os docentes. Dez escolas públicas e particulares de Belém participaram da pesquisa-intervenção, na qual utilizamos aulas-teatro como disparadoras do debate junto às professoras e professores. A partir dessa experiência, sistematizamos três categorias de análise: a) A ausência de discussão crítica sobre a medicalização da educação; b) A exigência do laudo; c) A falta de estrutura e investimento na formação continuada. Discute-se a carência de políticas que favoreçam práticas não medicalizantes no contexto educacional, bem como a necessidade de maior engajamento das escolas nesse debate.

Palavras-chave: medicalização; trabalho docente; intervenção social.

\section{Debating medicalization with teachers in public and private schools}

\begin{abstract}
This study aimed to find out how the topic of medicalization of education has been approached and debated among education professionals, more specifically teachers. Ten public and private schools in Belém participated in the intervention-research, in which we used theater-based classes as triggers for the debate with teachers. Based on this experience, we have systematized three categories of analysis: a) The absence of critical discussion about the medicalization of education; b) The requirement of the report; c) The lack of structure and investment in teacher training. The lack of policies that favor non-medicalizing practices in the educational context is discussed, as well as the need for greater involvement of schools in this debate.
\end{abstract}

Keywords: medicalization; teaching work; social intervention.

\section{Debatiendo sobre medicalización con docentes en escuelas públicas y privadas}

\section{RESUMEN}

En este estudio se tuvo como intuito conocer de qué forma el tema de la medicalización de la educación ha sido abordada y debatida entre profesionales de la educación, más específicamente las/los docentes. Diez escuelas públicas y privadas de Belém participaron de la investigación-intervención, en la cual utilizamos clases-teatro como disparadoras del debate junto a profesoras y profesores. A partir de esa experiencia, sistematizamos tres categorías de análisis: a) La ausencia de discusión crítica sobre la medicalización de la educación; b) La exigencia del laudo; c) La falta de estructura e investimento en la formación continuada. Se discute la carencia de políticas que favorezcan prácticas no medicalización en el contexto educacional, así como la necesidad de más participación de las escuelas en ese debate.

Palabras clave: medicalización; trabajo docente; intervención social.

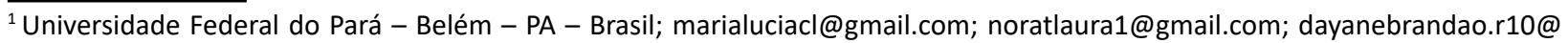
hotmail.com

${ }^{2}$ Instituto Federal do Pará - Belém - PA - Brasil; brunaacruz@gmail.com
} 


\section{INTRODUÇÃO}

Não é de hoje que escutamos que crianças e adolescentes não apresentam mais o mesmo padrão de comportamento dentro das escolas como as de antigamente. Sendo consideradas cada vez mais ágeis, inquietas, tímidas ou até mesmo desafiadoras, são subjetividades que configuram modos diversos de ser e viver contemporaneamente. Entretanto, é importante observar que em uma sociedade sujeita a regras e padrões de conduta que ditam como o ser humano deve se comportar, agir e, nessa lógica, como uma criança deve se desenvolver, esses modos não hegemônicos passam ser lidos a partir de lentes medicalizantes, que prontamente criam patologias, com seus devidos diagnósticos. Sendo assim, a dificuldade de aprender é entendida como sintoma de uma doença - hiperatividade, déficit de atenção, dislexia, depressões na infância etc. (Guarido \& Voltolini, 2009).

A medicalização da educação pode ser entendida pela expansão da jurisdição médica para o âmbito dos processos educacionais. Ou seja, as inquietações, conflitos, tensões, perturbações que estudantes experimentam e apresentam no cotidiano da sala de aula passam a ser interpretadas como doenças, tornando-se a origem do insucesso e fracasso escolar desse/a estudante. A medicalização da educação, portanto, refere-se ao poder com que a lógica biomédica adentra a escola e determina os padrões de normalidade dentro da vida escolar (Viégas, Harayama, \& Souza, 2015).

Desde que Ivan Illich (1982) passou a criticar as tendências de transformar as dores e questões da vida humana em temas de domínio médico, alguns teóricos e profissionais passam a se preocupar com os processos de medicalização engendrados na cultura ocidental.

Michel Foucault (2003) nos dá pistas das implicações históricas da medicalização da vida ao analisar o biopoder, forma de governo que tem na população e seus fenômenos de massa, como a saúde e a doença, seu objeto de preocupação e cujo propósito é governar a vida. Foucault (2003) analisou a entrada da vida no campo das técnicas políticas, "isto é, a entrada dos fenômenos próprios à vida da espécie humana na ordem do saber e do poder" (p. 133).

Com a emergência do capitalismo, o corpo passa a ser compreendido como a força motriz da sociedade. Enquanto o regime de soberania se constituía no direito de se apropriar das coisas, do tempo, dos corpos, da vida para a defesa da conservação de um Estado, o biopoder se apoia na incitação, no controle e na vigilância para criar, otimizar e ordenar as vidas e os modos de viver. O que está em jogo é a garantia da sobrevivência e do aproveitamento de uma população (Foucault, 2003).

Desse modo, a partir da segunda metade do século XVIII, a medicina passa a intervir em um campo mais amplo da existência do indivíduo e da população, apoiada pela integração do seu saber a estratégias emergentes de governo. "Desde o século XVIII, a medicina sempre se ocupou do que não Ihe dizia respeito, isto é, de aspectos diferentes dos doentes e das doenças" (Foucault, 2010, p. 182).

O objeto da medicina deixa de ser a doença, passando a ter como foco a vida de modo geral, favorecendo o controle social a partir da gestão dos riscos, periculosidades e outras virtualidades, atuando como prevenção. O que se percebe com isso é um progressivo processo de medicalização da vida, no qual algumas sensações físicas ou psicológicas, até então consideradas normais, são transformadas em sintomas de doenças. Insônia ou tristeza são assim interpretadas como distúrbios do sono e depressão, por exemplo (Meira, 2012). Nesse sentido, a medicalização também figura como resultado de práticas disciplinares que, na modernidade, tem como função caracterizar indivíduos, classificá-los, localizá-los e registrá-los na curva que os subjetiva como normal e anormal.

Atualmente, quase todo desvio, mesmo que pequeno, do que se considera normal pode ser diagnosticado, haja vista o aumento das doenças catalogadas no Manual Diagnóstico e Estatístico de Transtornos Mentais (DSM). Se em 1952, a primeira edição do DSM continha 106 categorias de desordens mentais, organizadas em 130 páginas, na última versão, lançada em 2013, o DSM-V listou 300 patologias distribuídas por 947 páginas (American Psychiatric Association, 1952; Associação Americana de Psiquiatria, 2014). Percebe-se, desse modo, o crescimento de um mecanismo que avalia as características pessoais, gostos ou preferências pelas lentes da normalidade versus anormalidade, tendo como referência e aval os saberes especializados da medicina e das neurociências.

A Educação, historicamente aliada a processos classificatórios e normalizadores, participa como importante ator desse processo de medicalização (Pizzinga \& Vasquez, 2018). Estudos voltados para esse campo apontam que o saber médico começa a adentrar no âmbito educacional a partir do final do século XVIII. De acordo com Decotelli, Bohrer e Bicalho (2013, p. 452), “o saber médico passa ter a missão de identificar os ditos anormais na medida em que a questão dos problemas de aprendizagem começam a tomar corpo. A causa da não aprendizagem é associada, desse modo, a fatores orgânicos".

Os atuais problemas de aprendizagem são frequentemente remetidos ao plano individual e orgânico, isentando docentes, escola, sistema de educação e todos os fatores sociopolíticos envolvidos. Ao converter fenômenos sociais em questões biológicas, esse processo de medicalização produz a individualização da questão, responsabilizando cada pessoa pelos seus problemas de aprendizagem, atribuindo-os a falhas em sua atividade 
neurológica, ou a uma suposta desestruturação familiar (Figueira \& Caliman, 2014).

Pizzinga e Vasquez (2018) alertam ainda para o efeito subjetivo que pode ter a produção de diagnósticos que rotulam crianças na tentativa de contornar as dificuldades em sua escolarização, considerando-se a sua força performativa. Coudry e Mayrink-Sabinson (2003) também apontam como os diagnósticos e tratamentos das pessoas produzem incessantemente sujeitos mudos e analfabetos, ocupando exatamente o lugar dos que não conseguem aprender. Desse modo, os sujeitos passam a se constituir como doentes e incapazes e, de fato, não conseguem se adequar ao ambiente escolar. Além disso, tal processo de medicalização provoca uma desvalorização crescente de professores, profissionais considerados cada vez menos aptos a lidar com tantas supostas patologias e distúrbios (Collares \& Moysés, 1994).

Outra problemática apontada pela literatura crítica a respeito da medicalização é que, por operar na transformação de questões não médicas em transtornos, acaba por gerar uma espécie de epidemia de diagnósticos, assim como de tratamentos, que muitas vezes podem causar danos à saúde, especialmente nos casos em que não seriam de fato necessários (Meira, 2012). Crianças diagnosticadas com TDAH, por exemplo, desde muito novas passam a tomar remédios psiquiátricos que podem afetar o sistema cognitivo futuramente. Percebe-se, desse modo, que a medicalização da educação é bastante vantajosa para a indústria farmacêutica, em constante crescimento mundial, e corresponde aos ideais de produtividade da sociedade contemporânea, pois oferece a ilusão de que boa parte dos complexos problemas humanos pode ser resolvida ao ingerir alguns comprimidos (Decotelli, Bohrer, \& Bicalho, 2013).

Diante desse contexto, este trabalho, realizado de 2016 a 2018 por um grupo de pesquisa vinculado a Universidade Federal do Pará (UFPA), teve como proposta investigar a forma como o tema da medicalização da educação tem sido abordado e debatido dentro das escolas. Professores e professoras sabem o que é medicalização da educação? Quais olhares lançam para os/as estudantes considerados problemáticos? Usam as lentes medicalizantes para ler as dificuldades de aprendizagem? Ou ampliam o debate, implicando outros fatores sociais para analisar essa questão?

Desse modo, o objetivo geral do presente estudo foi investigar, por meio de uma pesquisa-intervenção, como a medicalização da educação tem sido abordada em escolas de Belém (PA). Como objetivos específicos, elencamos: a) Realizar rodas de conversa sobre a medicalização da educação no contexto escolar; b) Analisar os discursos que circulam entre os/as profissionais da educação sobre a temática da medicalização; c) Refletir sobre as possibilidades de resistências ao processo de medicalização no contexto escolar.

Sendo assim, essa pesquisa não visou somente coletar as impressões de professores e demais membros da comunidade escolar sobre medicalização, mas também, e principalmente, fomentar modos de resistência à medicalização da educação. Trata-se de uma intervenção nos modos de entender os problemas de aprendizagem hoje vivenciados, atentando para as diversas formas de se viver e aprender.

\section{MÉTODO}

Este trabalho se configurou como uma pesquisa-intervenção acerca do debate sobre o processo de medicalização em escolas públicas e particulares da região metropolitana de Belém. Segundo Amador, Lazzarotto e Santos (2015), fazer uma pesquisa-intervenção é desestabilizar o instituído e acompanhar os movimentos que estão sendo e serão instituídos. Como investigação participativa que busca na intervenção coletiva a construção de espaços de problematização (Rocha \& Aguiar, 2003), a presente pesquisa-intervenção visou potencializar a reflexão sobre medicalização, favorecendo a transformação do cotidiano escolar, sendo, portanto, um ato político.

A seleção das escolas nas quais realizamos as intervenções foi feita primeiramente por meio de buscas nos sites das secretarias de educação municipal e estadual, que nos forneciam nome completo da escola, endereço e nome da pessoa responsável pela direção. Nossa preferência eram as escolas localizadas no distrito D'água do município de Belém pela proximidade da UFPA. Posteriormente, fizemos um mapeamento das escolas particulares na mesma região, utilizando um site de busca pela internet.

Com a lista das escolas existentes na abrangência territorial pesquisada, passamos a visitar as escolas, munidas de uma carta de apresentação da pesquisa, explicitando seus objetivos. Nessa ocasião, estabelecíamos uma conversa inicial com a pessoa responsável por nos receber nas escolas (gestores/as, coordenadores/ as pedagógicas), apresentando a pesquisa, o tema da medicalização e a proposta de intervenção.

Nessa conversa inicial, já recebíamos informações sobre como circulava o tema da medicalização na escola: casos de estudantes rotulados com alguma patologia ligada à dificuldade de aprendizagem, as práticas educacionais que os/as docentes utilizavam naquela instituição, a falta de conhecimento dos profissionais em relação ao tema que seria trabalhado, entre outros. Ainda nesse contato inicial, os/as gestores/as nos auxiliavam na construção da intervenção, pois conversávamos sobre qual público-alvo atingir (professores/as, estudantes, pais?), qual dia da semana mais propício para a participação da comunidade escolar na atividade etc. Dos quinze estabelecimentos 
educacionais visitados, cinco (duas escolas públicas e três particulares) não foram receptivas à proposta, justificando falta de agenda para inserir a intervenção na programação da escola. As demais aceitaram a proposta previamente apresentada, demostrando interesse no tema da medicalização e no formato da intervenção: aula-teatro seguida de uma roda de conversa com os/ as participantes.

A aula-teatro é uma encenação artística, contendo elementos de teatro, dança e performance, sobre um tema específico, de modo a incitar discussões, reflexões, diálogos. As aulas eram construídas em conjunto com o grupo de pesquisa por meio de oficinas de expressão corporal e laboratórios cênicos ministrados por um estudante concluinte do curso de licenciatura em Teatro da UFPA, bolsista do projeto. Nessas oficinas, preparava-se o corpo dos/as integrantes que participariam dessas intervenções, pondo em prática conceitos tais como espaços, modos de interpretação, de condução de cenas, entre outros. Nos laboratórios de construção das aulas-teatro, utilizávamos como inspiração alguns acontecimentos relacionados à medicalização com os quais os membros do grupo haviam tido contato.

A principal ferramenta trabalhada nos laboratórios cênicos foi o teatro do oprimido de Augusto Boal. Especialmente o teatro fórum, no qual se realiza uma encenação baseada em fatos reais, em que "oprimidos" e "opressores" entram em conflito, de forma explícita e objetiva, de modo que o "oprimido" (protagonista) fracassa e o "curinga", que faz a mediação entre palco e plateia, estimula o público a entrar em cena e refazê-la, para substituir alguém e tentar solucionar o problema encenado. No teatro fórum não existe, portanto, uma barreira entre palco e plateia, sendo o público constituído por espect-atores, que se tornam agentes de mudança do espetáculo e consequentemente atores sociais competentes para construir significados para a realidade que os cerca (Boal, 2014).

As aulas-teatro foram utilizadas em dez instituições educacionais (cinco particulares e cinco públicas) para disparar os debates que se seguiam, chamados aqui de rodas de conversa. De acordo com Melo e Cruz (2014, p. 32), a roda de conversa: "[...] permite que os participantes expressem, concomitantemente, suas impressões, conceitos, opiniões e concepções sobre o tema proposto, assim como permite trabalhar reflexivamente as manifestações apresentadas pelo grupo".

É importante ressaltar que a intervenção foi oferecida pela equipe de pesquisadoras para toda a comunidade escolar: docentes, gestores, funcionários estudantes e familiares. No entanto, os/as diretores/as das escolas geralmente optavam por realizar as intervenções durante a reunião da equipe docente, eventualmente convidando alguns estudantes para participar. $O$ público das intervenções variou entre 10 e 25 pessoas. A exceção foi em uma escola na qual a intervenção contou com a participação mais ampla da comunidade escolar, uma vez que a direção enviou convites para que os familiares pudessem participar, o que produziu uma interessante interação de diferentes posicionamentos sobre a questão. Essa intervenção contou com a participação de cerca de 40 pessoas. Por essa experiência ter sido a exceção, neste artigo optamos por analisar apenas as falas de docentes, uma vez que tiveram participações mais numerosas e se colocaram de forma mais engajada nos debates disparados pelas aulas-teatro.

Todo esse processo foi registrado por meio de diários de campos, nos quais eram anotados, da forma mais minuciosa possível, os acontecimentos ocorridos em campo, assim como as impressões subjetivas decorridas destes acontecimentos. Neles, não só as discussões das intervenções eram relatadas, mas também todo o caminhar que fora perpassado até conseguirmos realizá-las, evidenciando as facilidades, as dificuldades e até as resistências que foram encontradas, constituindo, assim, o material que será analisado neste texto.

No que se refere à escolha teórico-metodológica para a análise das informações produzidas, essa pesquisa é orientada a partir do construcionismo social, seguindo a análise de práticas discursivas e de produção de sentidos. Nesse contexto, a produção de sentidos é considerada uma prática social presente no cotidiano e no diálogo. Sendo a própria linguagem um suporte de tais práticas, o foco central de análise dessa perspectiva são as práticas discursivas: a linguagem em ação; os modos pelos quais as pessoas produzem sentidos e se posicionam em relações sociais cotidianas (Spink \& Medrado, 2013). Nessa pesquisa, portanto, buscou-se identificar as práticas discursivas dos professores sobre o tema da medicalização, a partir das anotações feitas no diário de campo das pesquisadoras.

A elaboração e posterior leitura do diário de campo ajudaram a identificar discursos relevantes abordados durante as intervenções, propiciando a sistematização das seguintes categorias de análise: a) A ausência de discussão crítica sobre a medicalização da educação; b) A exigência do laudo; c) A falta de estrutura e investimento na formação continuada.

\section{RESULTADOS E DISCUSSÃO}

\section{Ausência de discussão crítica sobre a medicalização da educação}

Nos caminhos percorridos dentro das redes municipal, estadual e privada de ensino da região metropolitana de Belém, encontramos vários discursos relevantes durante os processos de intervenção. Um dos discursos ou a ausência dele, nos causou inquietude: a falta de crítica ao processo de medicalização dentro das instituições educacionais.

Essa informação nos chamou atenção, uma vez que, 
como discutimos no início do texto, não é de hoje que a medicalização está presente em nossa sociedade e vem surtindo efeitos nocivos à vida. No entanto, nas quinze escolas visitadas, foi comum que as pessoas responsáveis por nos receber reagissem com estranhamento quando falávamos o tema da pesquisa: medicalização da educação. Quando questionávamos se já teriam escutado algo a respeito, a resposta era sempre negativa.

No entanto, logo percebemos que se tratava de um desconhecimento do termo medicalização, uma vez que, ao explicarmos a proposta de intervenção, a pessoa passava a citar vários casos de transtornos de aprendizagem. Portanto, não se conhecia o termo, mas a medicalização estava presente na prática. Sobre esse aspecto, elencamos dois pontos que podem ajudar a explicar esse acontecimento.

Em uma primeira instância, devemos reconhecer que a palavra medicalização em si já remonta um posicionamento crítico perante o processo que nomeia. 0 que notamos, portanto, é a falta de aproximação com as críticas a um processo - este sim conhecido - de entrada dos diagnósticos nas escolas, do fluxo entre escolas e serviços de saúde para avaliações neurológicas, entre outros processos que consideramos medicalização da educação.

A respeito disso, um aspecto que nos chamou atenção nas visitas às escolas foi uma certa dificuldade em se fomentar a discussão sobre a medicalização da educação nas instituições de ensino, sentida logo nos primeiros contatos. Como dito acima, ao chegar à escola, explanávamos sobre o tema e expressávamos nosso interesse em discuti-lo com o corpo docente e técnico. Muitas vezes, a pessoa que nos recebia (coordenadora, diretora da escola) perguntava se não poderíamos trabaIhar outro tema, tais como violência escolar, bullying etc. Entre as 15 escolas visitadas, cinco não demostraram interesse na intervenção proposta.

Observamos que, embora seja um tema relativamente novo, a falta de envolvimento na discussão sobre a medicalização da educação se mostra não por ser uma discussão restrita à universidade do ponto de vista técnico, mas pelo fato de, na Educação Básica, as escolas apresentarem dificuldades para viabilizar momentos que visam trabalhar a formação crítica desse/a docente.

De acordo com Barretto (2015), as dificuldades encontradas na formação de profissionais para a Educação Básica se fundam, no Brasil, em diferentes fatores históricos e sociais, entre eles, a expansão do acesso à educação, as mudanças no perfil socioeconômico e cultural dos/as docentes, bem como a precarização da formação inicial para a docência. Ainda segundo a autora, opera, nas políticas educacionais, a priorização de um "estilo gerencialista comandado pela avaliação de resultados nas políticas da educação básica" (Barretto, 2015, p. 698), um modelo baseado no cumprimento de metas em detrimento da tarefa fim da educação, a qual exige constante formação e transformação.

Nesse sentido, apontamos outro elemento que provavelmente contribui para a ausência desse debate na escola: as cobranças que professores/as enfrentam para cumprir os prazos que são impostos dentro das instituições escolares, como indica um professor participantes de uma das rodas de conversas empreendidas:

O professor não consegue dar atenção o suficiente para o estudante, devido aos prazos que a escola estipula para preparar o aluno para realizar "provinha Belém", a "provinha Brasil", mais a de avaliação da educação do estado, tornando complicado buscar formas para propor uma melhor educação (professor da rede estadual de ensino).

O excerto acima corresponde a um discurso recorrente entre os profissionais quando se questionava, no momento da roda de conversa, sobre o porquê de não discutirem criticamente a medicalização da educação.

É importante ressaltar que a carência de profissionais que discutem esse tema encontra-se não somente nas instituições escolares: trata-se de um debate incipiente entre as produções científicas da área da Pedagogia, como mostrou a revisão de literatura feita por Lima e Lima (2015).

Devemos considerar ainda o fato de que a medicalização, por ser tão imbricada à própria constituição da instituição escolar (Guarido, 2007), mistura-se no cotidiano como algo natural, não provocando necessariamente estranheza ou alerta. Como o próprio conceito sugere, a medicalização ocorre quando naturalizamos questões complexas, de cunho social, político, histórico, como questões biológicas e individualizantes (Collares \& Moysés, 1996), tornando dispensável uma análise crítica dos aspectos interpessoais e/ou coletivos da problemática.

Não é de hoje que a educação e a saúde se ocupam juntas de um processo de normalização dos corpos e dos comportamentos (Guarido, 2007), de modo que a própria formação acadêmica dos/as profissionais com que conversamos possivelmente teve como referência predominante uma educação para o desenvolvimento normal, condição atestada por especialistas da saúde, com privilégio do saber médico.

A formação dada aos professores contém informações de fundamentação biológica como base para a compreensão dos desvios e das instabilidades na escolarização e nos processos ensino-aprendizagem, de modo que

ao professor cabe continuar seu trabalho de sempre, agora tornado possível pela medicação nesses casos particulares, mas isso seria retomar a ideia de que um objeto entra para somar à lógica 
que está ali sem exigir nada de sua modificação. (Guarido \& Voltolini, 2009, p. 257).

Uma vez que as práticas classificatórias que localizam o desenvolvimento de estudantes nos limites entre normalidade e anormalidade são um fato histórico na vida escolar (Pizzinga \& Vasquez, 2018), a sua faceta neurocientífica mais contemporânea possivelmente é considerada antes um avanço tecnológico do que propriamente uma invasão da medicina.

\section{A exigência do laudo médico/psiquiátrico}

O saber médico está dentro das instituições escolares. Prova disso é a recorrente exigência por parte dos professores participantes da pesquisa da apresentação de um laudo médico/psiquiátrico que ateste o suposto transtorno de aprendizagem de estudantes considerados/as problemáticos/as. O laudo médico/psiquiátrico serve para certificar que o/a estudante de fato tem um problema de saúde; ou seja, é um instrumento visto com valor de verdade, já que é produzido por um profissional com grande prestígio e respeito social: o médico.

Essa demanda pelos laudos corresponde às práticas disciplinares que ganharam, na modernidade, a eficácia de caracterizar os indivíduos, classificando-os, localizando-os e registrando-os em uma curva que identifica a variação entre o normal e o anormal. Infelizmente, o que observa com essa exigência do laudo é que o saber médico ganha cada vez mais espaço para atuar como a verdade a ser seguida dentro da educação (Guarido \& Voltolini, 2009).

Uma vez comprovado o suposto problema de aprendizagem/comportamento via laudo médico, prevalece um sentimento de alívio, posto que o problema não está na escola, nos instrumentos pedagógicos ou outras questões sociais, mas sim, na doença. Localiza-se a fonte do problema: o/a estudante, ou melhor, a doença dele/a.

$\mathrm{O}$ alívio também se faz notar na relação pedagógica com esse/a estudante laudado/a, como é chamado pelo corpo docente. Parte desses/as docente afirmaram que o trabalho se torna menos árduo, tendo em vista que, nesses casos, recebem suporte da secretaria de educação. Além disso, as atividades repassadas aos/ às estudantes com algum tipo de patologia são mais leves, não apresentando o mesmo nível de dificuldade do repassado ao restante da turma.

Quando o aluno é diagnosticado e apresenta um laudo torna-se mais fácil de trabalhar, pois as secretarias do estado e do município oferecem um pequeno suporte para acompanhar este estudante, tornando assim o trabalho mais leve quando ele é diagnosticado, pois como possui certo transtorno ou patologia, não precisamos passar atividades mais difíceis, pois os mesmos não conseguiriam realizar devido ao transtorno que ele apresenta (professora da rede municipal de ensino).

Uma das poucas diferenças identificadas nessa pesquisa entre os discursos sobre medicalização que circulam entre professores das escolas públicas e privadas está circunscrita na questão do laudo médico. Nas escolas públicas, os professores avaliam que o laudo médico seria de grande utilidade para conduzir o trabalho pedagógico e, por isso, lamentam-se da dificuldade que é conseguir um atendimento médico para a maioria das crianças. O laudo é o ideal, ainda que não seja um instrumento tão frequente. Já nas escolas particulares, o laudo é uma presença mais constante na vida escolar. Em duas escolas visitadas, inclusive, o laudo médico que comprove (ou não) a existência de uma patologia é uma das exigências para a matrícula do estudante. Desse modo, todas as crianças precisam estar munidas de um laudo médico como exigência para a matrícula na escola. Essa informação mostra a intensidade da inserção do processo de medicalização no cotidiano escolar.

Sobre isso, Guarido e Voltolini (2009) afirmam que os/as profissionais das escolas esperam que um laudo com um diagnóstico proferido por um especialista os indique a metodologia correta de ensino para lidar com esses/as estudantes laudados/as, ajudando-os a sair da ignorância e da inadequação às crianças e jovens que têm diante de si. Ou seja, o trabalho docente passa a ser desvinculado do papel de avaliar e propor quais formas mais eficientes para conduzir o ensino, conferindo-se esse papel a saberes especializados da área da saúde.

Além da crítica à importância que o laudo médico está tomando na vida escolar, é preciso atentar ainda para o próprio procedimento de encaminhar os alunos que não correspondem às expectativas de aprendizagem e de comportamento a especialistas. Tal encaminhamento tende a individualizar a queixa e os conflitos gerados a partir dela, fortalecendo, assim, os processos de medicalização (Souza, 2007).

\section{A falta de estrutura e de investimento na formação continuada dos profissionais da educação}

A terceira categoria que destacamos, entre os pontos expostos pelos/as professores/as, principalmente nas intervenções feitas nas escolas públicas, é a falta de estrutura física das escolas. As escolas particulares muitas vezes também não contavam com uma estrutura física satisfatória, no entanto, talvez pela pouca liberdade de criticar um estabelecimento privado, os professores pouco mencionaram essa questão.

A falta de infraestrutura necessária, tanto para o 
processo de ensino e aprendizagem, quanto para o acoIhimento e atendimento dos alunos em geral, mas principalmente daqueles que apresentam algum problema de aprendizagem ou comportamento, é grande e precisa ser sanada. No entanto, a carência não se restringe aos recursos materiais, como exposto neste trecho retirado do diário de campo de uma das pesquisadoras:

Duas professoras que estavam na roda de conversa começaram a explanar sobre as dificuldades presentes no ambiente de trabalho. Primeiramente abordaram sobre a problemática de salas superlotadas, nas quais são postos 25, 30 e até 35 crianças para a educação infantil e o ensino fundamental menor [...]. As cobranças realizadas pelos superiores da escola, principalmente relativas aos prazos, contribui para que os professores não possam dar a devida atenção para cada estudante.

Não somente as salas superlotadas, mas também os cortes na educação, redução de carga horária, carência de espaços adequados para determinadas atividades escolares são alguns dos elementos elencados pelos professores como obstáculos para uma educação de qualidade.

Nesse sentido, não se pode culpabilizar tais profissionais pelo estado em que as instituições escolares se encontram ou pela ausência de conhecimento em relação à crítica sobre a medicalização da educação. De acordo com uma professora do 4 ano do ensino fundamental de uma escola municipal: "Os professores estão preocupados em realizar um bom trabalho, em trazer atividades diferentes para estes alunos, porém, a escola não possui um recurso midiático, nem um atrativo para tornar esta educação melhor".

Outros elementos apontados pelos professores convergem para a ausência do Estado em disponibilizar uma formação adequada para trabalhar com os novos temas que surgem na educação. Em nossas intervenções, era notório o surgimento de falas que abordavam sobre esta falta de investimentos tanto nas estruturas da instituição quanto nos processos de formação continuada do profissional da educação, principalmente quando questionávamos se era debatido o conceito de medicalização da educação dentro daquele ambiente escolar. A ausência de investimento na formação continuada de professores/as reflete de maneira negativa quanto ao domínio que eles/as demonstram em relação a novos conhecimentos, metodologias e temas que surgem dentro do contexto educacional.

O Estado não disponibiliza uma formação que trabalhe com os novos temas que surgem na educação, pois [...] se o professor tivesse conhecimento, o tratamento com essas crianças seria diferente, uma vez que até evitaria o processo de rotulação e medicalização, já que tendo um pouco de conhecimento sobre este assunto, a interpretação do comportamento do mesmo seria totalmente diferente (professor da rede estadual de ensino).

A formação continuada, além de auxiliar os profissionais da educação a saber lidar com as novas demandas que surgem no contexto educacional, proporciona novos olhares, interpretações e ações diante dos métodos, temas e concepções que circundam o ambiente educacional.

O investimento em uma formação continuada crítica, atenta às discussões políticas em voga, é uma arma poderosa contra o estabelecimento de práticas medicalizantes na educação. No entanto, no cenário político atual, sabe-se que tal investimento está distante de figurar o interesse de nossos gestores, porque a medicalização está a seu serviço, operando no controle das resistências políticas pelo silenciamento dos conflitos (Lemos, 2014).

\section{CONSIDERAÇÕES FINAIS}

Ao contrário do que imaginávamos no início da pesquisa, não encontramos diferenças significativas entre os discursos de professores da rede particular e pública de ensino. Mesmo frente ao crescimento da medicalização da educação, a maioria dos profissionais que participaram das nossas intervenções desconheciam a temática. Falavam de doenças, de dificuldades de aprendizagem, mas não remetiam essas questões a um processo de medicalização da educação, muito menos à crítica sobre a patologização dos modos de viver.

No entanto, percebemos a presença/exigência mais constante do laudo médico/psiquiátrico nas escolas privadas. Professores de escolas públicas e privadas valorizavam esse recurso, mais como um instrumento que os exime de exigências pedagógicas ao/à estudante laudado/a do que como um incentivo a buscar novas práticas pedagógicas para tais estudantes. No entanto, é nas escolas particulares que o laudo se faz mais presente, tanto que, para nossa surpresa, uma das exigências para a matrícula de estudantes em algumas instituições particulares visitadas é a apresentação de laudos que comprovem a existência ou não de uma patologia.

De outro lado, são os professores da rede pública de ensino que mais reclamam da falta de estrutura da escola e de investimento na educação continuada de professores. Talvez por se sentirem mais confortáveis em exigir tais demandas do Estado ou Município do que os professores de uma instituição privada, que supostamente exigiriam dos/as proprietários/as da escola.

De modo geral, são notórios os desafios que a escola 
tem para acolher as necessidades de seus/suas estudantes sem medicalizá-los/as. Uma pessoa em processo de desenvolvimento enfrenta vários impasses e dificuldades. O enfrentamento de tais dificuldades é o próprio motor que faz com que a aprendizagem aconteça. O/a professor/a sem essa compreensão acaba por interpretar tais dificuldades como sintomas de patologias ou transtornos, passando, mesmo sem intenção, a rotular aquele indivíduo que não tenha obtido o sucesso escolar nas atividades que lhe são propostas. Portanto, faz-se necessário criar espaços de reflexão sobre a medicalização e, desse modo, criar resistência a esse processo.

Isso significa também fazer frente aos processos adjacentes à medicalização, que, conforme discutimos nesse estudo, são exatamente os conflitos que sofrem silenciamento pelos fluxos e práticas medicalizantes que vivenciamos: a precarização do trabalho, a falta de investimentos na educação e a culpabilização de indivíduos pelo fracasso escolar.

Entre as práticas que podem e devem ser realizadas como resistência e afirmação de outras formas de se fazer educação, apontamos: implicar a escola como um todo na construção de projetos pedagógicos; discutir e refletir sobre iniciativas e estratégias que deram certo; prezar por espaços de elaboração coletiva de estratégias educacionais, bem como fortalecer fluxos escola-comunidade estabelecendo diálogo de modo a favorecer o processo educacional.

A formação continuada também é de absoluta importância para que a educação cumpra seu principal papel, que é transformar a sociedade. As dificuldades encontradas apontam para um complexo emaranhado de fatores estruturais que se apresentam como obstruções a esse processo. Considerando as limitações das soluções oferecidas pelas políticas públicas de formação docente, compreendemos que espaços de troca entre as universidades e as escolas constituem situações frutíferas para o avanço do processo formativo em questão.

Nesse sentido, acreditamos que essa pesquisa-intervenção contribuiu como uma das alternativas possíveis para se trabalhar a discussão crítica sobre a medicalização da educação, que é tão importante nas escolas. Ainda que de modo inicial e longe de ter esgotado o debate, acreditamos que momentos como esses têm sua parcela de contribuição, uma vez que se pautam no diálogo sensível entre ciência e prática profissional.

Sugerimos, portanto, que outras pesquisas pautadas em ações interventivas, por meio do diálogo e da convivência entre diferentes atores da área educacional, sejam realizadas, no sentido de fomentar o avanço de estratégias de formação que contemplem cada vez mais a realidade que construímos historicamente nesse campo social.

\section{REFERÊNCIAS}

Amador, F. S.; Lazzarotto, G. D. R.; Santos, N. I. S. (2015). Pesquisar-Agir, Pesquisar-Intervir, Pesquisar-Interferir. Rev. Polis e Psique, 5(2), 228-248. doi: 10.22456/2238$152 X .58180$

American Psychiatric Association (1952). Diagnostic and statistical manual of mental disorders. Washington, DC: American Psychiatric Association. Recuperado de: https:// ia800701.us.archive.org/10/items/dsm-1/dsm-1952.pdf.

Associação Americana de Psiquiatria (2014). Manual Diagnóstico e Estatístico de Transtornos Mentais. Porto Alegre: Artmed, 5a ed.

Barretto, E. S. S. (2015). Políticas de formação docente para a educação básica no Brasil. Revista Brasileira de Educação, 20(62), 679-701. doi: 10.1590/S1413-24782015206207.

Boal, A. (2014). Teatro do Oprimido: e outras poéticas políticas. São Paulo: Editora Cosac Naify.

Collares, C. A. L.; Moysés, M. A. A. (1994). Transformação do espaço pedagógico em espaço clínico (a patologização da educação). Fundação para o Desenvolvimento da Educação - Série Idéias, n.23, 25-31.

Coudry, M. I. H.; Mayrink-Sabinson, M. L. (2003). Pobrema e dificulidade. In: E. Albano; Coudry, M. I. H.; Possenti, S.; Alkmim, T. (Ed.), Saudades da língua (pp. 561-576). Campinas: Mercado de Letras.

Decotelli, K. M.; Bohrer, L. C. T.; Bicalho, P. P. G. (2013). A droga da obediência: medicalização, infância e biopoder - Notas sobre clínica e política. Psicologia: Ciência e profissão, 33(2), 446-459. doi: 10.1590/S1414-98932013000200014.

Figueira, P. L.; Caliman, L. V. (2014). Considerações sobre os movimentos de medicalização da vida. Psicologia Clínica, 26(2), dez., 17-32. Recuperado de http://www. scielo.br/scielo.php?script=sci_arttext\&pid=S0103$56652014000200002 \& \operatorname{lng}=p t \& \operatorname{tng}=$ pt.

Foucault, M. (2003). História da sexualidade: Vol.1. A vontade de saber. Rio de Janeiro: Edições Graal.

Foucault, M. (2010). Crise da medicina ou crise da antimedicina (H. Conde, Trad.). Verve, 18, 167-194.

Guarido, R. (2007). A medicalização do sofrimento psíquico: considerações sobre o discurso psiquiátrico e seus efeitos na educação. Educação e Pesquisa, 33(1), 151-161. doi:10.1590/S1517-97022007000100010

Guarido, R; Voltolini, R. (2009). O que não tem remédio, remediado está? Educação em Revista, 25(1), 239263. Recuperado de: https://www.scielo.br/pdf/edur/ v25n1/14.pdf

Illlich, I. (1982). A expropriação da saúde: nêmesis da medicina. Rio de Janeiro: Forense.

Lemos, F. C. S. (2014). A medicalização da educação e da resistência no presente: disciplina, biopolítica e segurança. Psicologia Escolar e Educacional, 18(3), 485-492. doi: /10.1590/2175-3539/2014/0183772 
Lima, L. N.; Lima, M. L. C. (2016). Medicalização da educação: uma análise sobre a produção bibliográfica brasileira (Relatório de Pesquisa Pibic-Pard/2015). Instituto de Educação, Universidade Federal do Pará, Belém - PA.

Meira, M. E. M. (2012). Para uma crítica da medicalização na educação. Psicologia Escolar e Educacional, 16(1), 135-142. doi: 10.1590/S1413-85572012000100014

Melo, M. C. H.; Cruz, G. de C. (2014). Roda de Conversa: uma proposta metodológica para a construção de um espaço de diálogo no Ensino Médio. Imagens Da Educação, 4(2), 31-39. doi: 10.4025/imagenseduc.v4i2.22222.

Pizzinga, V. H.; Vasquez, H. R. (2018). Reificação, inteligência e medicalização: formas históricas e atuais de classificação na escola. Psicologia Escolar e Educacional, 22(1), 123-131. Doi:10.1590/2175-35392018012840.

Rocha, M. L.; Aguiar, K. F. (2003). Pesquisa-Intervenção e a Produção de Novas Análises. Revista Psicologia
Ciência e Profissão, 23(4), 64-73. doi:10.1590/S141498932003000400010

Souza, B. P. (2007). Orientação à queixa escolar. São Paulo: Casa do Psicólogo.

Spink, M. J.; Medrado, B. (2013). Produção de sentido no cotidiano: uma abordagem teórico-metodológica para análise das práticas discursivas. In: Spink, M. J. (Ed.), Práticas Discursivas e Produção de sentidos no cotidiano: Aproximações teóricas e metodológicas (edição virtual, pp. 22-41). Rio de Janeiro: Centro Edelstein de Pesquisas Sociais. ISBN: 978-85-7982-068-7.

Viégas, L. S.; Harayama, R. M.; Souza, M. P. R. (2015). Apontamentos críticos sobre estigma e medicalização à luz da psicologia e da antropologia. Ciência \& Saúde Coletiva, 20(9), 2683-2692. doi:10.1590/141381232015209.08732015

Recebido: 22 de abril de 2019 Aprovado: 16 de dezembro de 2019 